Dennis Eusebio A. Baladiang, MD

Mildred B. Olveda, MD

Eduardo C. Yap, MD

Department of Otorhinolaryngology

Head and Neck Surgery

Ospital ng Makati
Correspondence: Dennis Eusebio A. Baladiang, MD Department of Otorhinolaryngology-Head and Neck Surgery 5th floor Ospital ng Makati

Sampaguita St. cor Gumamela St. Pembo Makati City 1218 Philippines

Telefax: 8826316 loc 309

Email: denshoMed2000@gmail.com

Reprints will not be available from the author.

No funding support was received for this study. The authors signed a disclosure that they have no proprietary or financial interest with any organization that may have a direct interest in the subject matter of this manuscript, or in any product used or cited in this article.

Presented at Surgical Innovation Contest (1st Place), Philippines Society Of Otolaryngology Head and Neck Surgery 53rd Annual Convention, Edsa Shangrila Manila, Philippines December 2009

\section{The "Sail" Excision Technique: A Modified Alar Lift Procedure for Southeast Asian Noses}

\author{
ABSTRACT \\ Objective: To describe a new "sail" shaped excision technique for alar lift surgery and present the \\ outcome of this technique through photo documentation.
}

\section{Methods:}

Design: Surgical Innovation; Case series

Setting: Tertiary Government Hospital

Participants: Four patients underwent alar rim lift procedure using "sail" excision technique performed by the senior co-author. The indication for "sail" excision technique was a hanging ala (type IV) based on the classification of alar-columellar discrepancies by Gunter et al. The outcomes were described with comparison of pre-operative and post-operative photographs.

Results: Post-operative improvement of the alar-columellar relationship and counter-rotation of the tip, the "gull's wing in flight" was further enhanced. There were no scar contracture or vestibular stenosis, and scars were aesthetically acceptable.

Conclusion: Alar lift surgery demands an accurate diagnosis and analysis of the alar-columellar discrepancies. In Southeast Asian noses, unlike Caucasian noses, the most common indication for alar surgery are wide and overhanging ala. Our proposed technique is an easy and safe method of correcting alar overhang. This procedure with its advantages represents a new, reliable and simple way of achieving predictable results in many rhinoplasty cases.

Keywords: alar lift, hanging ala, alar-columellar relationship, alar-columellar discrepancies, counterrotation of tip, vestibular stenosis

Alar lift surgery is an integral part of any rhinoplastic procedure but is often overlooked by surgeons performing rhinoplasties. This alar lift is usually indicated in Asian noses which often require re-contouring or re-shaping of the nostril to achieve symmetry and appropriate size and to correct alar overhang. ${ }^{1}$ It is also used in re-contouring cleft lip noses, equalizing asymmetrical nostrils, enlarging small nostrils, converting round to oval nostrils and correction of alar overhang.' The alar overhang gives a poor aesthetic relationship of the alar rim with columella as exemplified by the low wings of the "gull's wing in flight" appearance.

Overhanging alae are a common feature in Southeast Asian noses notably of Malayan origin. Countries included are Cambodia, Indonesia, Malaysia, Singapore, Thailand, Vietnam, Myanmar and the Philippines. Such features are also seen in Taiwan, Hong-kong and Southern China. ${ }^{2}$

The standard management of an overhanging ala involves a horizontal ellipse incision on 


\section{SURGICAL INNOVATIONS AND INSTRUMENTATION}

Philippine Journal Of Otolaryngology-Head And Neck Surgery

VOL. 25 No. 1 JANUARY - JunE 2010

PJOHIS

the vestibular skin. ${ }^{3}$ While experienced rhinoplastic surgeons may be able to rely on their aesthetic judgment, we believe that this technique is quite risky and difficult especially for inexperienced surgeons. This technique involves partial excision of the vestibular skin which may lead to over-resection resulting to distortion of the anatomy and disorientation of the surgeon.

We introduce a simple yet reliable technique to lift the ala and correct the overhang through a "sail" excision.

\section{SURGICALTECHNIQUE}

The alar lift can be performed any time during rhinoplasty but it is advised to have it done as the initial step because of the easy manipulation on everting the alar rim starting from marking to incision to suturing.

The procedure starts with careful assessment of the alar-columellar relationship and identification of the important landmarks of the "sail". Markings are performed on the vestibular side of the ala with a "sail" shaped or an isosceles triangle (2 sides and a base) (Figure 1). The "apex" starts at the peak of the "gull's wing-in- flight" (Figure 2). The caudal side is along the alar rim while the cephalic side is along the vestibular groove (Figure 3). The groove is located few millimeters inferior-lateral to the caudal-lateral margin of the upper lateral cartilage (Figure 4). Alternatively, it can also be identified along the demarcation of the hair bearing and non-hair bearing area on the lateral vestibular wall. The base is usually at the area where the nasal sill ends. In cases associated with wide alar base and alar flaring, wherein concomitant alar base and sill excision are required, it will be appropriate to put its markings prior to "sail" incision as to avoid overlapping and properly place the base of the "sail" incision.

After all the markings are placed, the vestibular wall is infiltrated with $2 \%$ lidocaine $\mathrm{HCL}$ and 1:100,000 units of epinephrine assuming that the patient is usually under IV sedation. This step is accomplished using a 10cc syringe with 30 gauge needle. Three to five minutes are allowed to elapse for complete analgesia and vasoconstriction. A no.15 blade is used to perform the "sail" incision. The initial incision may be carried out along the base or any of the sides of the "sail" and continued to complete the "sail" excision on whatever preferred side of the triangle (Figure 5A). The incision along the cephalic side should parallel the contour of the vestibular groove. The vestibular skin is excised together with a moderate amount of subcutaneous tissue (Figure 5B). It is essential not to expose the opposite dermis of the alar skin. The retained subcutaneous tissue will somehow ensure a smooth contour of the alar rim. This step is usually accomplished with minimal bleeding and electrocauterization is seldom necessary. The same procedure should be done on the contralateral ala. Needless to say, symmetry in this procedure is essential.

The vestibular defect is closed in a single layer of simple interrupted nylon 6.0 suture (Figure 6A). Due to uneven length of the "sail" excision,

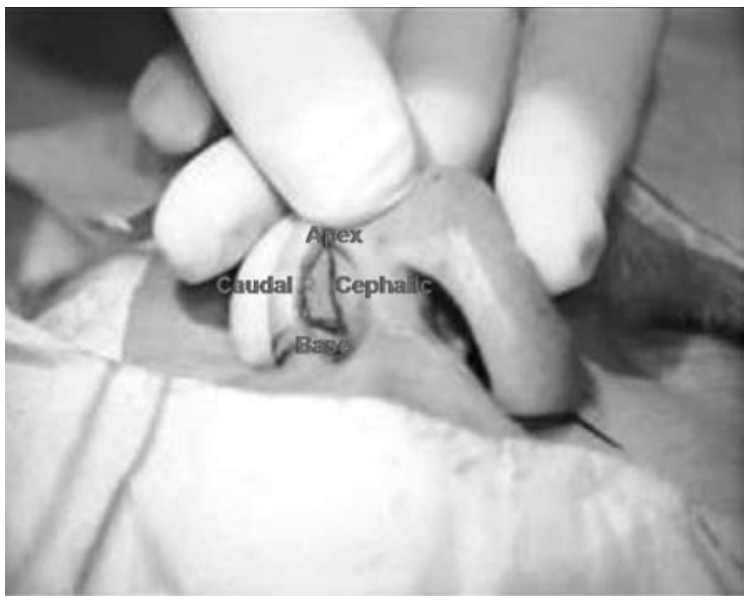

Figure 1. Markings on the vestibular side of ala
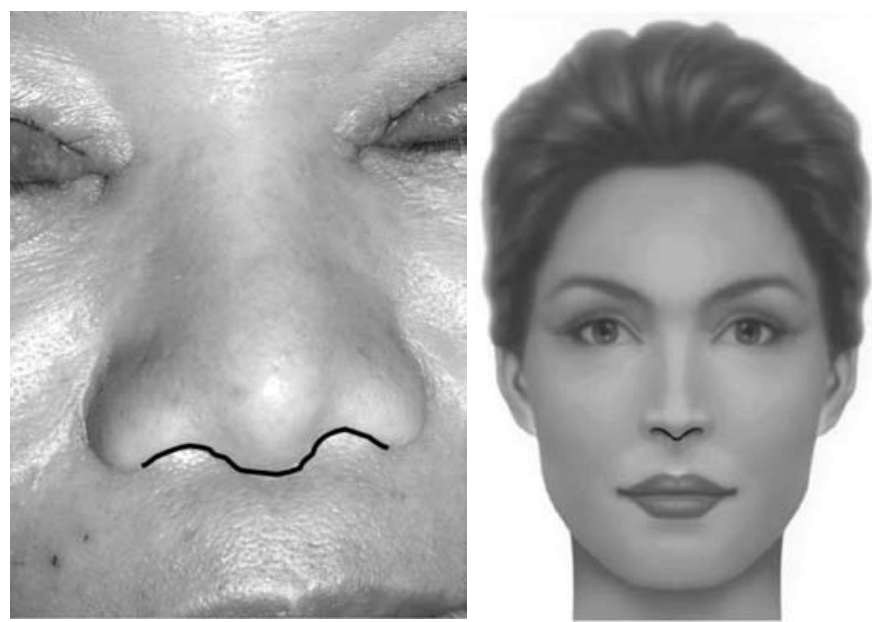

Figure 2. The gull's wing-in-flight (relationship of nasal ala with the infra-tip lobule). [Adapted from Paper ID. Orten SS, Hilger PA. Facial Plastic and Reconstructive Surgery. New York: Thieme; 2002. $2^{\text {nd }}$ ed chap. 31p. 364]

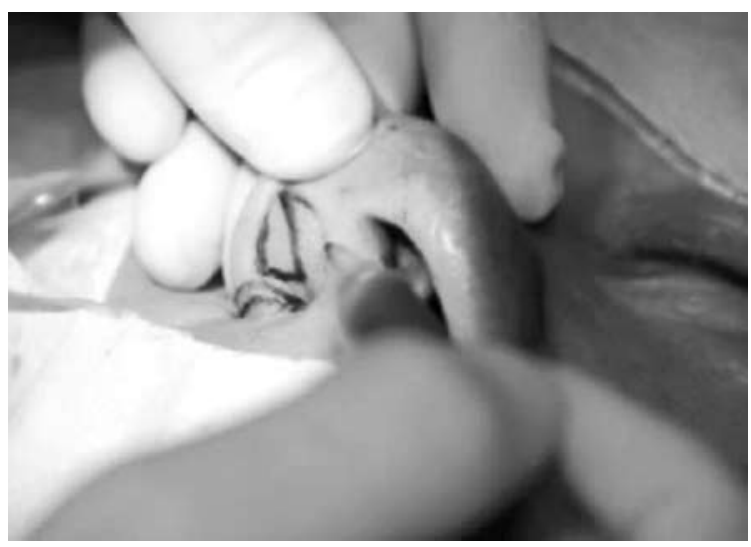

Figure 3. Boundaries of the "Sail" Incision 


\section{SURGICAL INNOVATIONS AND INSTRUMENTATION}

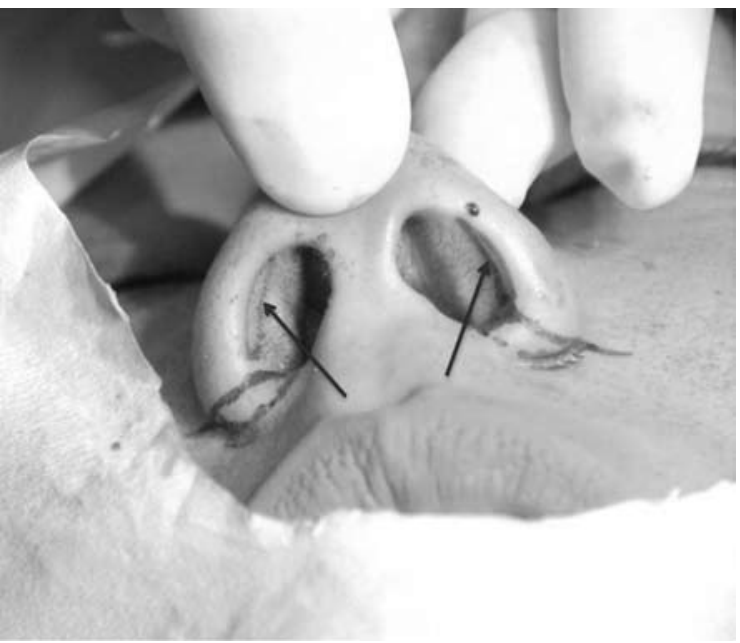

Figure 4. Vestibular groove (arrow)
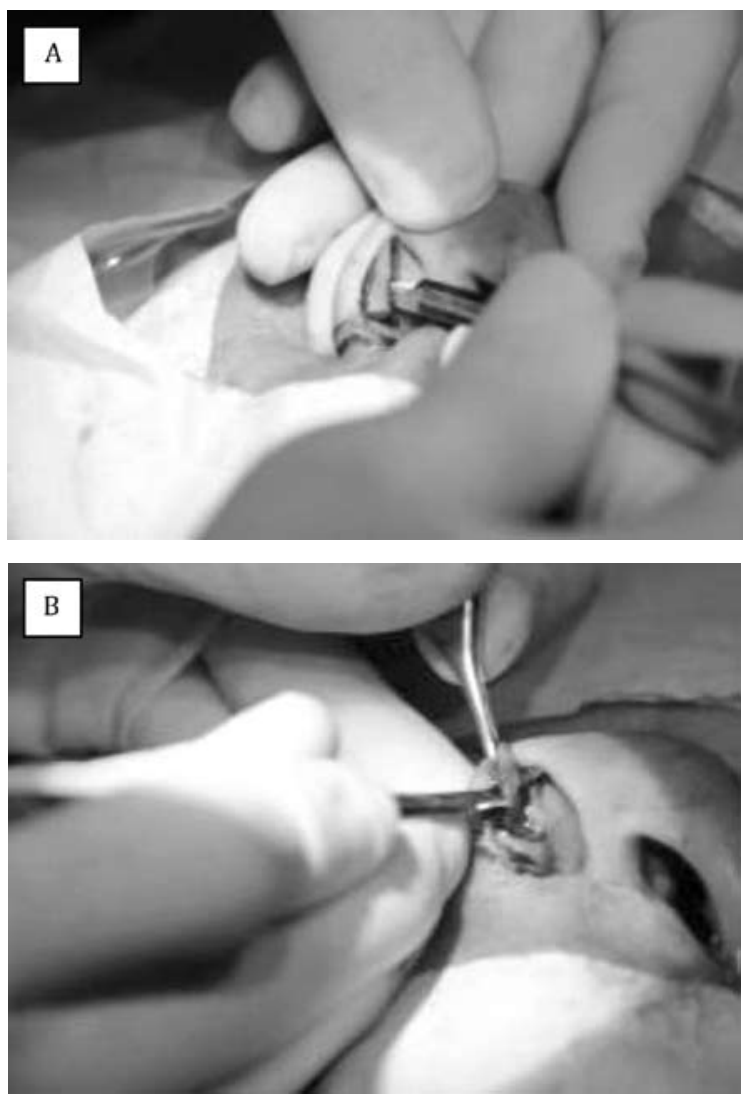

Figure 5. Vestibular skin incision. Incision noted at the border of hair bearing and non-hair bearing area (A). Excision of vestibular skin with subcutaneous tissue (B)

vestibular skin approximation starts on both ends of the defect (apex and base) and adjustments are made during closure (Figure 6B). It is important not to suture too tightly or leave the sutures more than 5 to 7 days. Occasionally, there may be suture indentations but these usually smooth out in time.
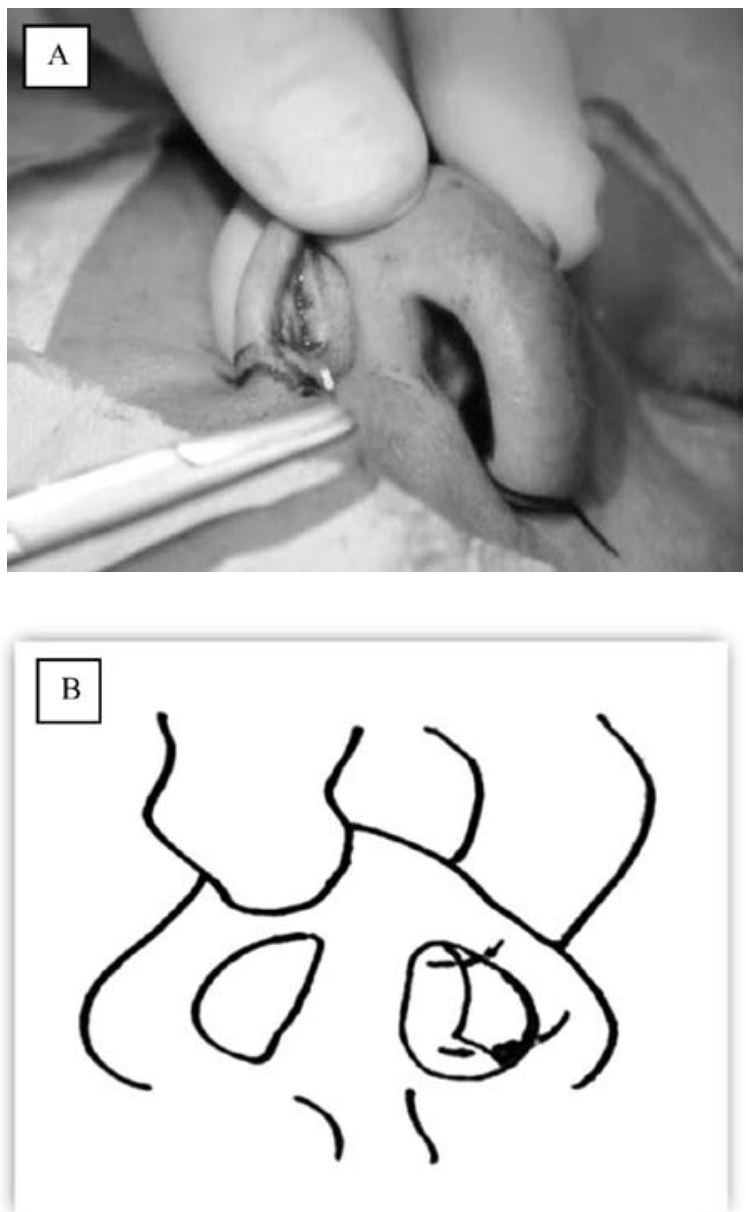

Figure 6. Closure of nasal vestibular defect. "Sail" shape defect after removal of excised vestibular skin (A). Schematic illustration showing approximation starting at both ends of the defect (B).

The optimum height of the lift can be calculated by the length of the base excised divided into half. Therefore, a $4 \mathrm{~mm}$ excision at the base can give a $2 \mathrm{~mm}$ alar lift (Figure 7). The inherent variability on the location of the cephalic incision from the vestibular groove gives the surgeon flexibility to adjust the amount of tissue to be excised. This manner of excision and closure essentially creates a flap from the sidewall of the alar rim towards the vestibular defect, thus creating a new alar rim from the lateral rim skin. Lastly, the outcome can be appreciated intraoperatively (Figure $8 A$ and $B$ ).

\section{CASE SERIES}

\section{Case 1}

A 24-year-old male health care provider complained of wide ala and rounded tip, he also requested to have his nose augmented. Physical examination showed low dorsum, wide alar base and overhanging ala. The plan was to do augmentation of the dorsum, alar base trimming and alar rim lift. The tip also had to be modified using tip sutures. The 


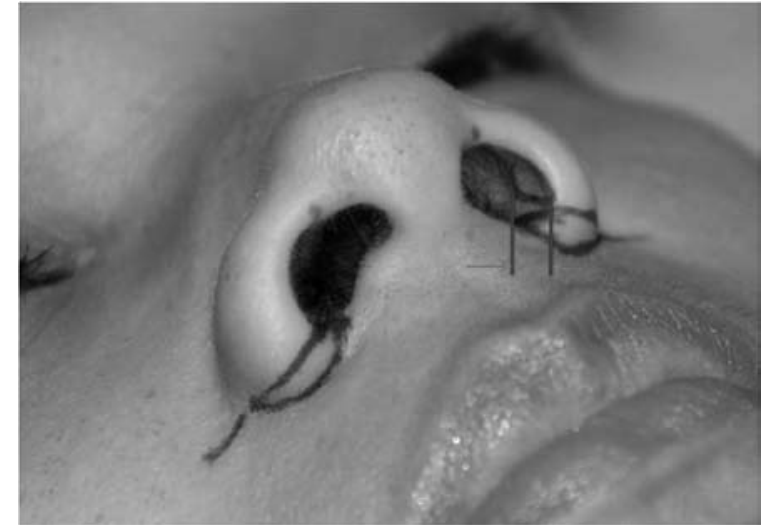

Figure 7. The optimum lift is approximated by length of base divided by 2 .
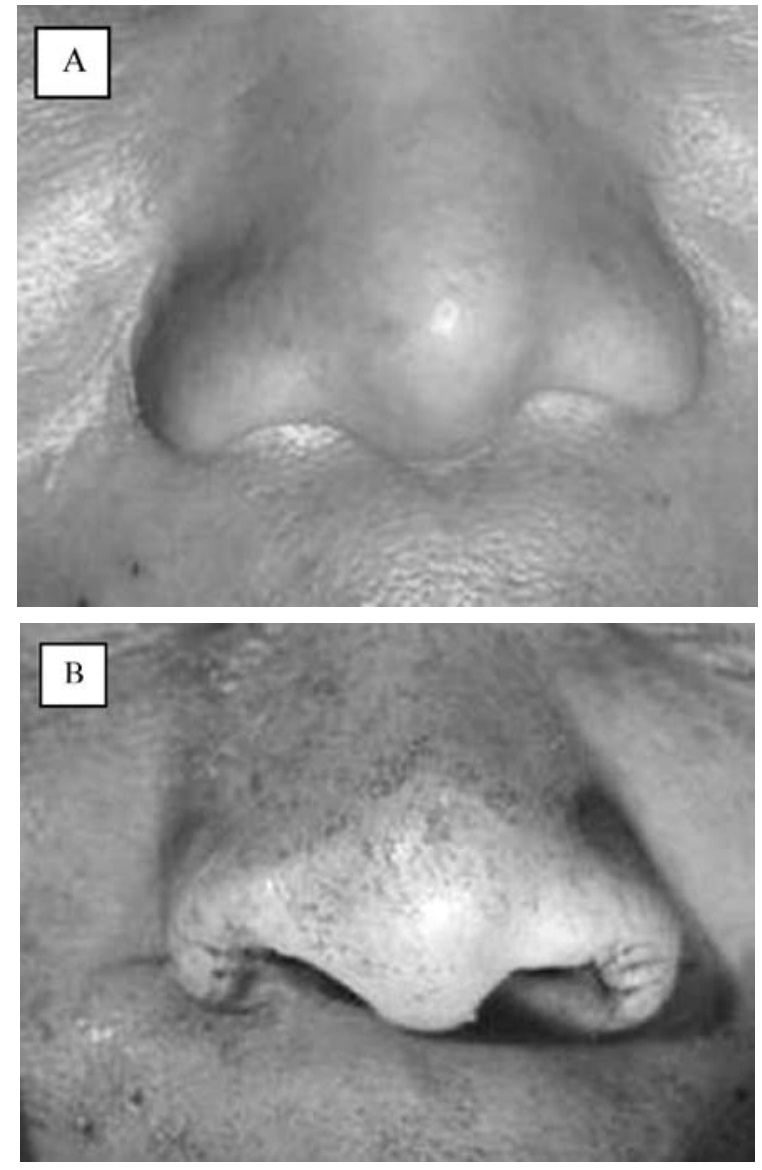

Figure 8. . Intra-operative alar rim effect. Before (A); After (B):

patient requested for rib cartilage as material for dorsal augmentation. The $7^{\text {th }}$ rib cartilage was harvested and used for the following grafts: Dorsal augmentation and columellar strut, shield graft with back stop were used for tip counter-rotation. Surgery was done under closed technique. Further enhancement procedures performed to improve the alar-columellar relationship were the alar base excision with bunching and alar rim lift via "sail" excision technique (Figure 9A-E).
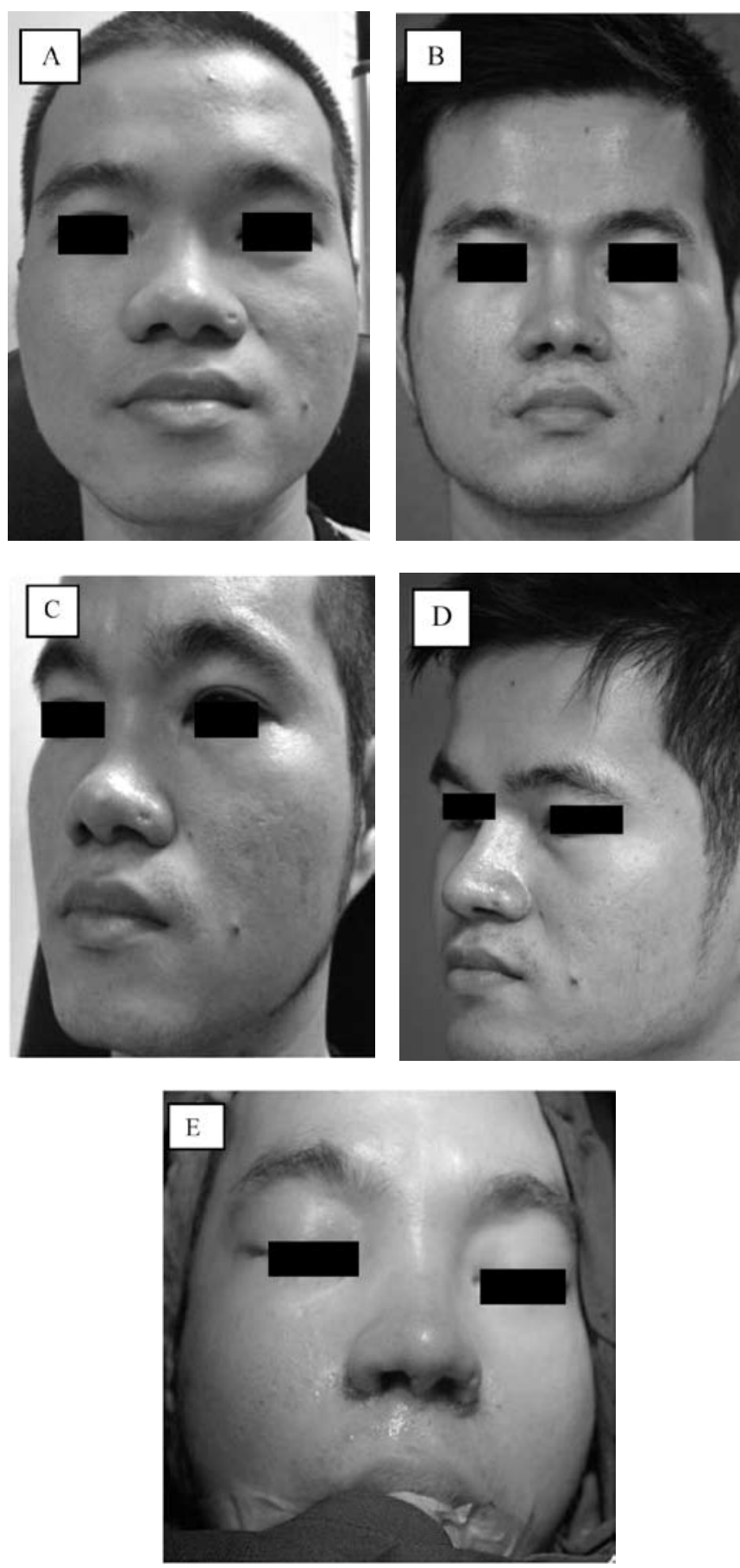

Figure 9. (Case 1) Pre-operative photographs show a low dorsum, wide alar base and overhanging ala (A and $C$ ); photographs taken immediately post-operative $(E)$ and 1 year after the surgery showed improvement of the alar-columellar relationship, tip projection and counter-rotation look of the tip ( $B$ and D). The $7^{\text {th }}$ rib cartilage was used for dorsal augmentation, columellar strut and shield graft. 


\section{SURGICAL INNOVATIONS AND INSTRUMENTATION}

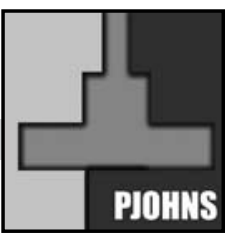

\section{Case 2}

A 24-year-old female health care provider complained that her nose was too big and the tip was too rounded. Physical examination revealed a short nose, rotated (bulbous) tip, wide ala, overhanging alar rim, low dorsum, retracted columella and premaxilla. Since the nose was short and rotated, it was deemed necessary to lengthen the nose with strong structural material. Rib cartilage was the appropriate graft to be used. An open approach was done to expose the whole structural framework including the septum. A septoplasty (submucous resection) was performed wherein the quadrangular cartilage was harvested. The rib and septal cartilages were carved into appropriate sizes for the following structural grafts: dorsal augmentation, bilateral extended spreader graft, columellar strut graft, alar strut graft, premaxillary augmentation, shield graft with back stop and onlay perichondrium as camouflage graft. Alar base excision with bunching and alar rim lift surgery via "sail" excision technique were further performed to improve the alar-columellar relationship (Figure 10A-E).

\section{Case 3}

A 35-year-old female health care provider complained that she had a wide ala and rounded tip. Physical examination showed a rounded (bulbous) tip, lower dorsum, wide alar base and overhanging alar rim. The plan was to do dorsal augmentation, tip refinement surgery, septoplasty for cartilage harvest, alar base excision and alar rim overhang correction. The procedure was performed via closed technique. Dorsal augmentation was accomplished using two sheets of $3 \mathrm{~mm}$ expanded polytetrafluoroethylene (e-PTFE), Gore-Tex ${ }^{\circledast}$ (Gore Industries, Worldwide). Septoplasty (submucous resection) for cartilage harvest was used for columellar strut and shield graft, cephalic trim of lower lateral cartilage, domal suturing, interdomal suturing, alar base excision and bunching and alar overhang correction via surgery via"sail" excision technique were done to improve alar-columellar relationship (Figure 11A-D).

\section{Case 4}

A 23-year-old male health care provider complained of rounded tip and wide ala. Physical examination showed a rounded (bulbous) tip, wide alar base and overhanging alar rim. The plan was to perform correction of the bulbous tip via cephalic trim of lower lateral cartilage, tip suturing, defatting and further enhancement by radix augmentation, alar base excision and alar rim lift. Surgical approach was closed technique. Nasal septal cartilage was harvested via transfixion incision. Tip refinement surgery done was by cephalic trimming of lower lateral cartilage, domal and interdomal suturing technique with columellar strut and shield grafts. Radix augmentation accomplished using one sheet of $3 \mathrm{~mm}$ expanded polytetrafluoroethylene (e-PTFE), Gore-Tex ${ }^{\oplus}$ (Gore Industries, Worldwide). Alar base excision with bunching and alar
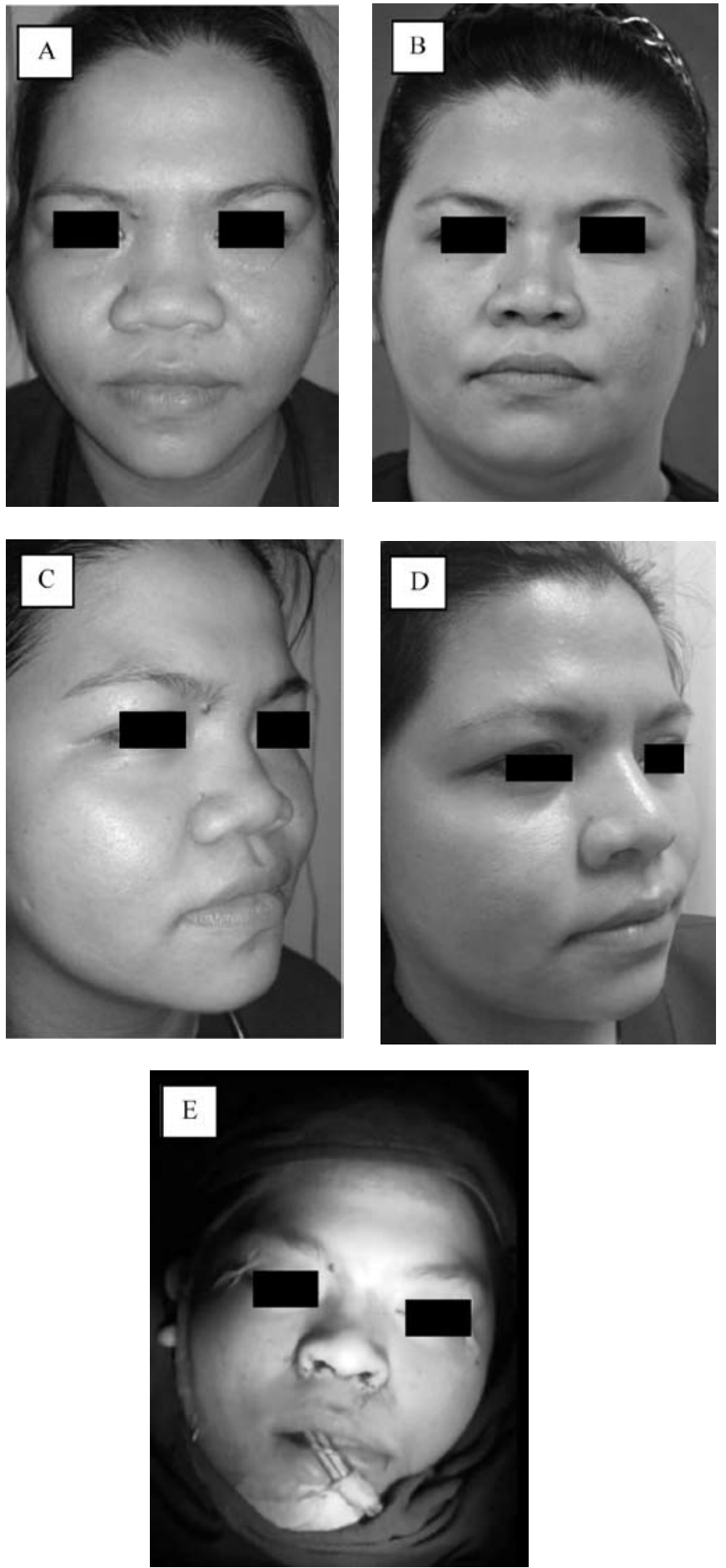

Figure 10. (Case 2) Pre-operative photographs show short nose, bulbous tip, low dorsum, retracted columella, wide ala and overhanging alar rim (A \& C); photographs taken immediately post-operative (E) and 1 year after surgery which demonstrated improvement of the alar-columellar relationship and counter-rotation of tip, the "gull's wing in flight" was further enhanced. The $7^{\text {th }}, 8^{\text {th }}$ rib and septal cartilages used for dorsal augmentation, bilateral extended spreader graft, columellar strut graft, alar strut graft, premaxillary augmentation and shield graft. 

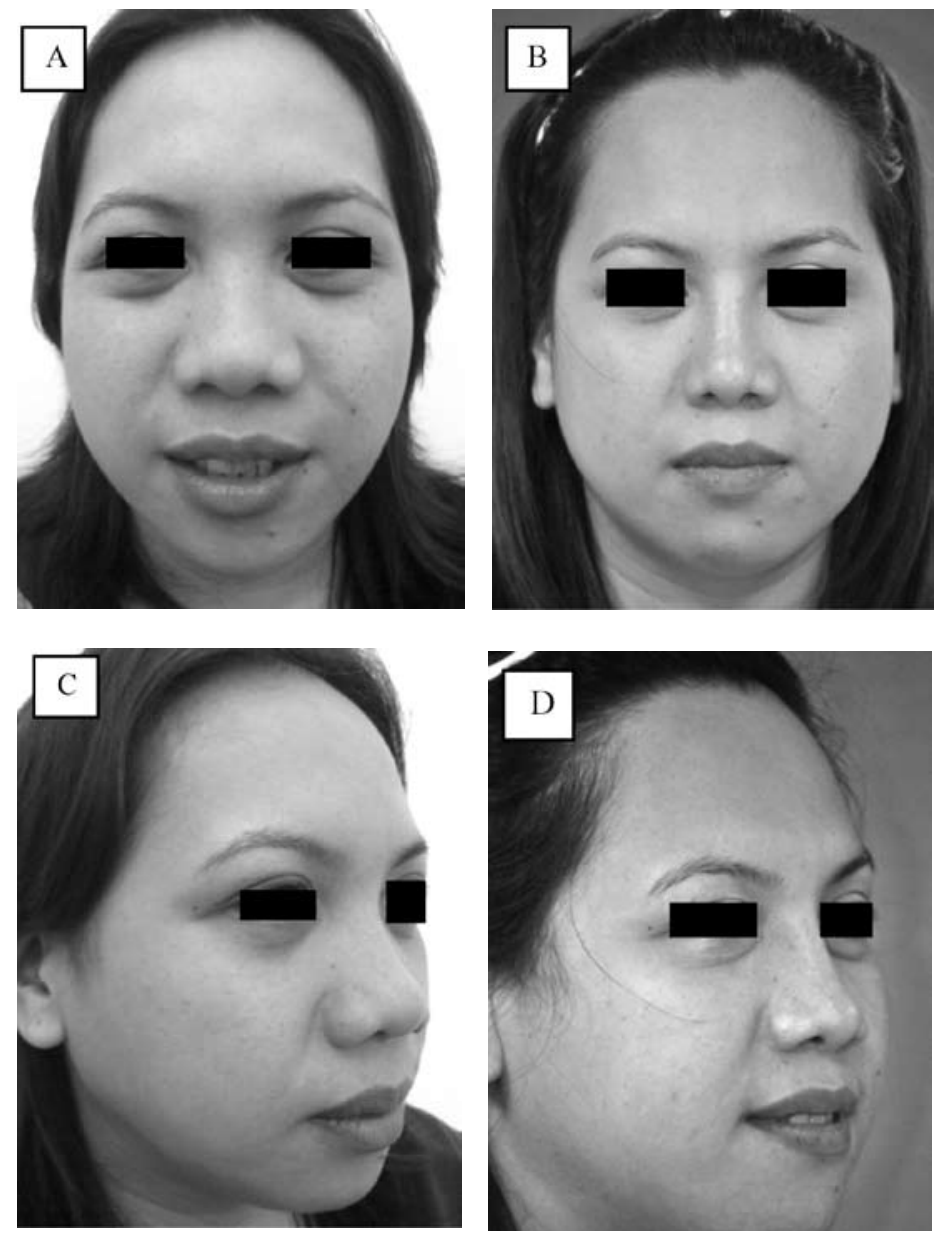

Figure 11. (Case 3) Pre-operative photographs show low dorsum, bulbous tip, wide ala and overhanging alar rim (A\&C); photographs taken 1 year after surgery, post-operative views demonstrate desired alar-columellar relationship and counter-rotation of tip (B and D). Note the "gull's wing in flight" appearance of the ala which was further modified. Dorsal augmentation was accomplished using 2 sheets of $3 \mathrm{~mm}$ e-PTFE (Goretex) and septal cartilage for various tip grafting.

rim lift surgery via "sail" excision technique were further performed to improve the alar-columellar relationship (Figure 12A-D).

\section{DISCUSSION}

In an ideal alar-columellar relationship, the greatest distance from the long axis of the nostril to either alar rim or columella should be 1-2 $\mathrm{mm}^{3}$ (Figure 13). A columella to nostril axis distance of $<1 \mathrm{~mm}$ or $>2 \mathrm{~mm}$ indicates a retracted or hanging columella respectively. Conversely, an ala to nostril axis distance of $<1 \mathrm{~mm}$ or $>2 \mathrm{~mm}$ corresponds to hanging or retracted ala respectively. ${ }^{3}$ It is requisite to understand the alar-columellar relationship for proper assessment and correction of abnormal relationship (Figure 14). In addition, on lateral view of the ideal nose, the nostril is oval with the alar rim forming the superior nostril border and the roll of the columella forming the inferior border. The alar rim is cephalad to and parallel to the columella. On front view, it should have the gentle "gull's wing in flight" appearance. ${ }^{4}$
Several techniques in alar lift surgery have been proposed. Mckinney advocated excision of the nasal lining in the cephalic border of the alar cartilage and caudal to the internal nasal valve. ${ }^{5}$ Ellenbogen used the technique of direct excision of the skin for hanging ala. ${ }^{1}$ Millard described the alar margin sculpturing through shaping the thinning in conjunction with alar base excision. ${ }^{6}$ Gunter further described this idea, suggesting a 3-mm horizontal elliptical incision on the vestibular skin will raise the hanging ala up to $2-\mathrm{mm}^{3}$

In our opinion, an excision on the nasal lining adjacent to the internal nasal valve without a definite landmark is difficult and may damage the nasal valve area. A direct external excision on the skin especially on heavier tissue of the nose particularly among thick skinned individuals may lead to roughness of the alar rim and possibly noticeable scarring.

All our patients presented with features of Southeast Asian nose of Malay race described here as one with low dorsum, rounded (bulbous) tip, wide and overhanging ala sometimes a retracted columella and drooping tip.

In this series, our patients underwent several procedures like tip grafting, columellar and alar base surgery as indicated. Rhinoplasty in Asian Malay noses is a very challenging task for it requires not only improvement on the height of the bridge but also requires improvement on the tip and ala. In order to achieve good aesthetic result with Asian Malay noses, lower cartilage surgery, tip augmentation (cartilage or synthetic), alarplasty, alar base bunching and alar overhang correction must be accomplished. To address problems associated with the tip and ala, the "sail' technique was applied in all the patients. The advantage of including this technique as a procedure of choice for correction of overhanging ala was the considerable improvement of the alar-columellar relationship. In addition, it also gives a good counter-rotation look of the tip. Since all of the incisions were placed in the vestibular skin, an inconspicuous scar was well hidden in the depth of the normal alar rim lining. The limitation of this technique is its role in severely retracted columella wherein a septo-columellar extension graft could be used to achieve the best aesthetic result.

The technique we proposed may be somewhat similar to procedures popularized by other rhinoplastic surgeons. Bearing in mind the advantages and benefits of performing alar lift surgery, the procedure was further modified by adapting well defined surgical landmarks that serve to guide the extent of vestibular excision as well as to the amount of skin tissue to be removed.

Finally, potential complications of the sail excision technique include hypertrophic scar at the alar rim (Figure 15), vestibular stenosis and scar contracture which can be attributed to unlevelled closure of skin and post-operative infections. These complications have not been observed in this series.

Alar lift surgery demands an accurate diagnosis and analysis of alarcolumellar discrepancies. In Southeast Asian noses, unlike Caucasian 


\section{SURGICAL INNOVATIONS AND INSTRUMENTATION}
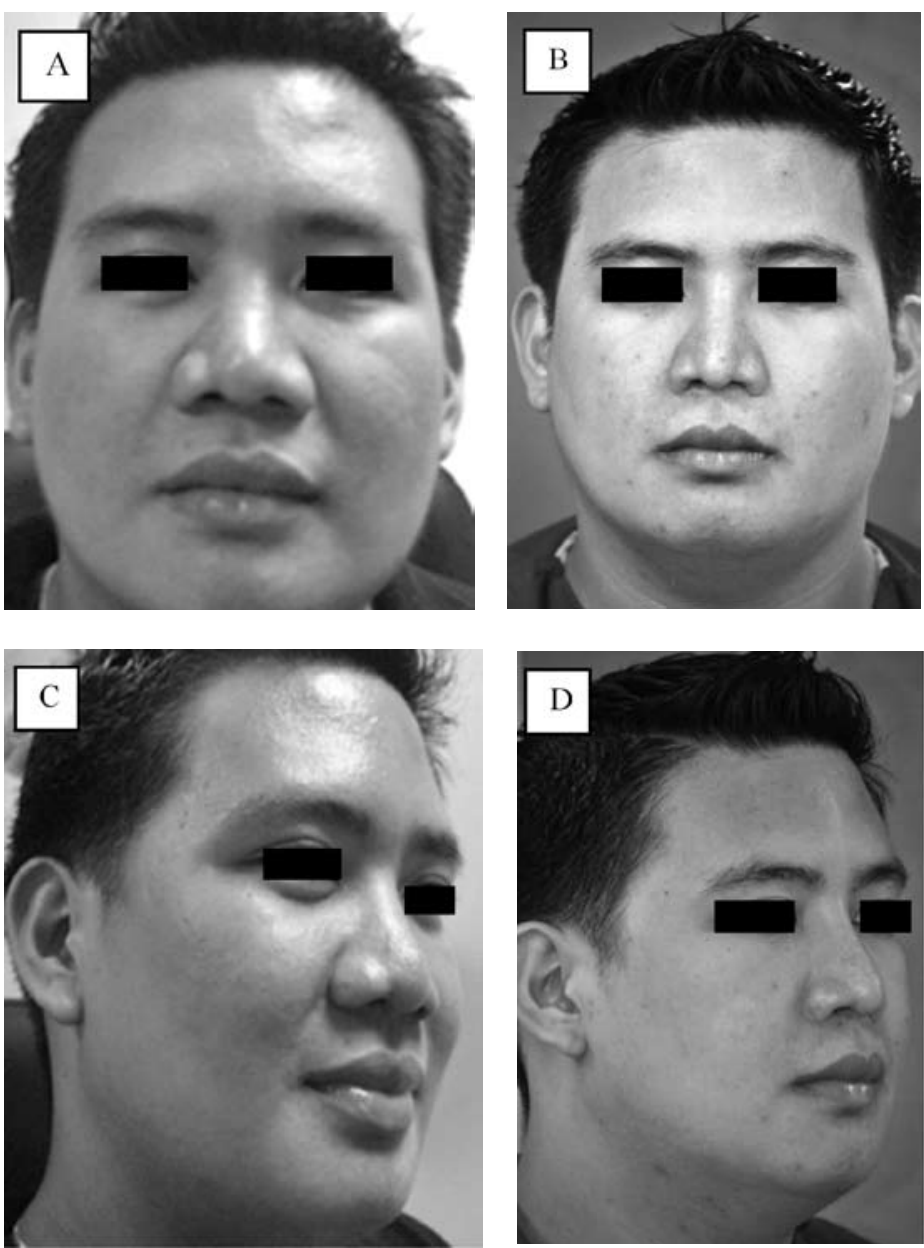

Figure 12. (Case 4) Pre-operative photographs show rounded tip, wide alar base, overhanging ala rim (A and C); photographs taken 1 year after operation show improved alar-columellar relationship. cephalic trim of lower lateral cartilage, tip suturing, defatting, radix augmentation (e-PTFE), alar base excision and alar rim lift (B and D)

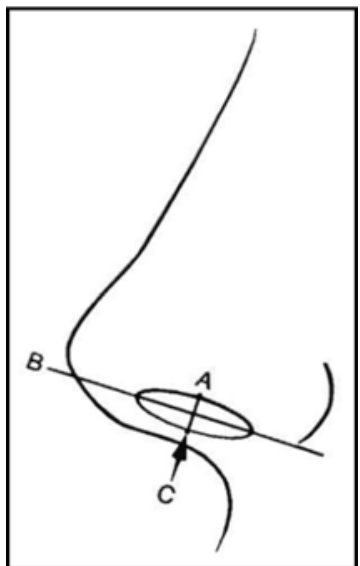

Figure 13. Ideal alar-columellar relationship, the greatest distance from the long axis of the nostril to either the alar rim or the columella should be 1 to $2 \mathrm{~mm}$, or $A B=B C=1$ to $2 \mathrm{~mm}$ [Adapted from Gunter JP: Classification and Correction of Alar-Columellar Discrepancies in Rhinoplasty. Plast. Reconstr. Surg., 97: 3, 1996] noses, the most common indication for alar surgery are wide and overhanging ala. Our proposed technique is an easy and safe method of correcting alar overhang. This procedure, with its advantages, represents a new, reliable and simple way of achieving predictable results in many rhinoplasty cases.

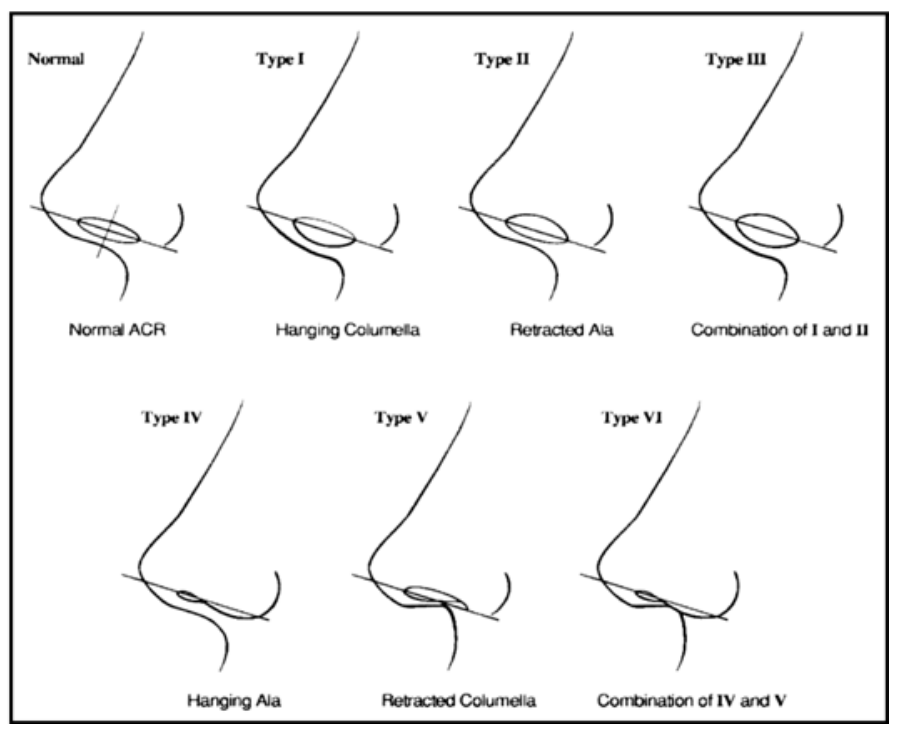

Figure 14. Classification of alar-columellar discrepancies [Adapted from Gunter JP. Classification and Correction of Alar-Columellar Discrepancies in Rhinoplasty. Plast. Reconstr. Surg., 97: 3, 1996]

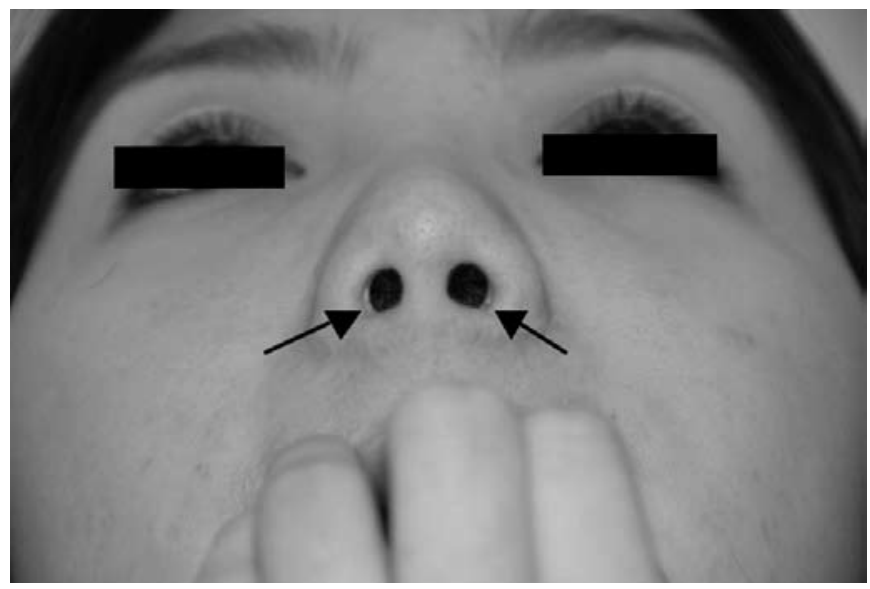

Figure 15. Formation of hypertrophic scar along the alar rim (arrow)

\section{REFERENCES}

1. Ellenbogen R, Blome DW. Alar Rim Raising. Plast Reconstr Surg. 1992 Jul;90(1):28-37

2. Yap EC. Components in Asian Malay Rhinoplasty. $4^{\text {th }}$ Annual Rhinoplasty Course Ospital ng Makati 2006 (Unpublished Lecture); 2006 Jun

3. Gunter JP, Rohrich RJ, Friedman M. Classification and Correction of Alar-Columellar Discrepancies in Rhinoplasty. Plast Reconstr Surg. 1996 Mar;97:643-48

4. Paper ID, Orten SS, Hilger PA. Facial Plastic and Reconstructive Surgery. New York: Thieme; 2002. $2^{\text {nd }}$ ed chap. 31p. 364

5. Mckinney P. Stalnecker ML. The Hanging Ala. Plast Reconstr Surg. 1984 Mar;73(3):427-30

6. Millard R. Alar Margin Sculpturing. Plast Reconstr Surg. 1967 Mar;40(4);337-42 